\title{
ORIGINAL ARTICLE \\ Value of Anti-Müllerian Hormone in Diagnosis and Management of Children with Disorders of Sex Development
}

\author{
Hossam Mostafa Kamal ${ }^{1}$, Ashgan Abd-Allah Al-Gobashy ${ }^{1}$, Ebtehag Helmy Hassan ${ }^{2}$, Ibrahim \\ Shawky Ibrahim ${ }^{3 *}$ \\ ${ }^{1}$ Pediatrics Department, Faculty of Medicine, Zagazig University, Zagazig, Egypt \\ ${ }^{2}$ Clinical Pathology Department, Faculty of Medicine, Zagazig University, Zagazig, Egypt \\ ${ }^{3}$ Pediatrics Department, Belbeis Central Hospital, Sharkia health affairs, Zagazig, Egypt
}

*Corresponding Author:

Ibrahim Shawky Ibrahim;

Pediatrics Department, Belbeis

Central Hospital, Sharkia health affairs, Zagazig, Egypt

Ibrahimshawky123@gmail.com

$\begin{array}{ll}\text { Submit Date } & 2019-03-30 \\ \text { Revise Date } & 2019-05-05 \\ \text { Accept Date } & 2019-05-09\end{array}$

ABSTRACT

Background: The aim of the study was to investigate the serum levels of Anti-Müllerian hormone (AMH) in children with disorders of sex development and its correlation with other diagnostic investigations to assess the ability of $\mathrm{AMH}$ to predict the presence and function of testicular tissue. Methods: The study was carried out at the pediatric, pediatric surgery and clinical pathology departments at Zagazig University Hospitals (ZUH) during the period from February 2018 to December 2018. The study was performed on 40 infants and children below the age of ten years. They were divided into two groups, control and DSD groups, each group contained 20 participants. Children were subjected to full history taking, precise clinical examination, and investigations that included ultrasonography, karyotyping and biopsies. In addition, serum $\mathrm{AMH}$, testosterone and dihydrotestosterone (DHT). Statistical analysis using suitable significance tests was performed. Results: Specificity and sensitivity of testosterone and DHT in detection of testicular activity were $100 \%$ for both while they were $91.7 \%$ and $100 \%$ respectively for AMH in 46,XY DSD. Conclusion: Serum testosterone and DHT had a better diagnostic role in 46.XY DSD than AMH while in 46,XX DSD, AMH is better.

Keywords: AMH, DSD, testosterone, dihydrotestosterone.

\section{INTRODUCTION}

D. isorders of sex development (DSD) are congenital conditions associated with atypical sex development. They include a wide range of disorders and syndromes that can be classified according to the chromosomal pattern into sex chromosome DSD (Turner syndrome, Klinefelter syndrome, etc.), 46,XY DSD (gonadal dysgenesis, androgen insensitivity syndrome, etc.) and 46,XX DSD (CAH, POR gene defect, etc.) [1]. The global incidence of DSD worldwide is $1 / 4500$ birth [2]. In North, South America and Western Europe, $\mathrm{CAH}$ is the most common type, accounting for approximately $70 \%$ of DSD cases [3].

Anti-Müllerian hormone (AMH) is a dimeric peptide hormone secreted by Sertoli cells. It is expressed in male embryos by the seventh gestational week to guide the differentiation of embryo into male genital tract and prevent the involution of Müllerian ducts into female genital tracts [4]. AMH, being a product of Sertoli cells, can reflect the presence and function of testes in boys without any need for testicular stimulation by human chorionic gonadotropic (HCG) hormone [5].

\section{Study design}

The study is a case control study that was carried out at Zagazig University Hospitals 
(ZUH) during the period from February 2018 to December 2018. It was performed on 40 infants and children who were divided into two groups, control and DSD groups.

The DSD group included 20 members who had a confirmed diagnosis with any type of DSD, while the control group included 20 members who attended to ZUH with minor irrelevant symptoms.

Ethical approval for the study was obtained from the Institutional Review Board (IRB) at the faculty of medicine, Zagazig University. Written informed consent was obtained from all participants' parents. The work has been carried out in accordance with The Code of Ethics of the World Medical Association (Declaration of Helsinki) for studies involving humans.

\section{Methods}

After history taking, general and local examination the following investigations were done:

i. Ultrasonography was done using high resolution B-mode system with broadband linear probe of $13 \mathrm{MHz}$.

ii. Chromosomal analysis was done in the molecular and cytogenetics laboratory in ZUH.

iii. Gonadal Biopsies: for 4 patients with bilateral cryptorchidism were subjected to histopathological gonadal biopsies prior to the start of the study.

iv. Estimation of serum levels of AMH, testosterone and dihydrotestosterone by enzyme-linked immunosorbent assay (ELISA)

v. Statistically analysis: was performed using IBM SPSS Statistics, version 24 (IBM; Armonk, New York, USA). Continuous data were presented as Mean \pm SD if normally distributed or median (range) if not normally distributed. Categorical data were presented by the frequency and percentage. Normality was checked by Shapiro-Wilk test. Homogeneity of variance was checked by Levene's test. Chi-squared test of association, Fisher's Exact Test, Kruskal-Wallis H test, unpaired t-test, Mann-Whitney $U$ test and Spearman's correlation were used to detect significance. Receiver operating characteristic (ROC) curve was used also to measure the accuracy of $\mathrm{AMH}$, testosterone and DHT as diagnostic tests. $P$-value $<.05$ indicates a significant difference, $P<.01$ indicates a highly significant difference, $P<.001$ indicates a very highly significant difference while, $P \geq .05$ indicates a non-significant difference [6].

\section{RESULTS}

Parenteral consanguinity where a highly statistically significant difference between healthy and DSD children was found $(P<.001)$, as consanguinity was significantly high in DSD children as shown in Table 1. Children with perineal hypospadias or persistent Müllerian duct syndrome had also either unilateral or bilateral undescended testes shown in Table 2. Five cases of the 6 DSD females included in study were on proper hormonal therapy while only one was presented for the first time during a crisis. Healthy male children had very highly significantly higher anti-Müllerian hormone, higher testosterone and DHT levels than male DSD children $(P<.001)$. On the contrary, their levels were not significantly different between healthy female and female DSD children $(P>.05)$, as shown in Table 4. Anti-Müllerian $\mathrm{f}$ hormone, DHT and testosterone levels were not significantly different in male DSD children grouped according to ultrasonography findings ( $P>.05)$, as shown in Table 5. Table 6 shows a very highly statistically significant positive strong correlation between serum anti-Müllerian hormone level and testosterone level $(P<.001)$. 
Table 1.Baseline characteristics of healthy and DSD children

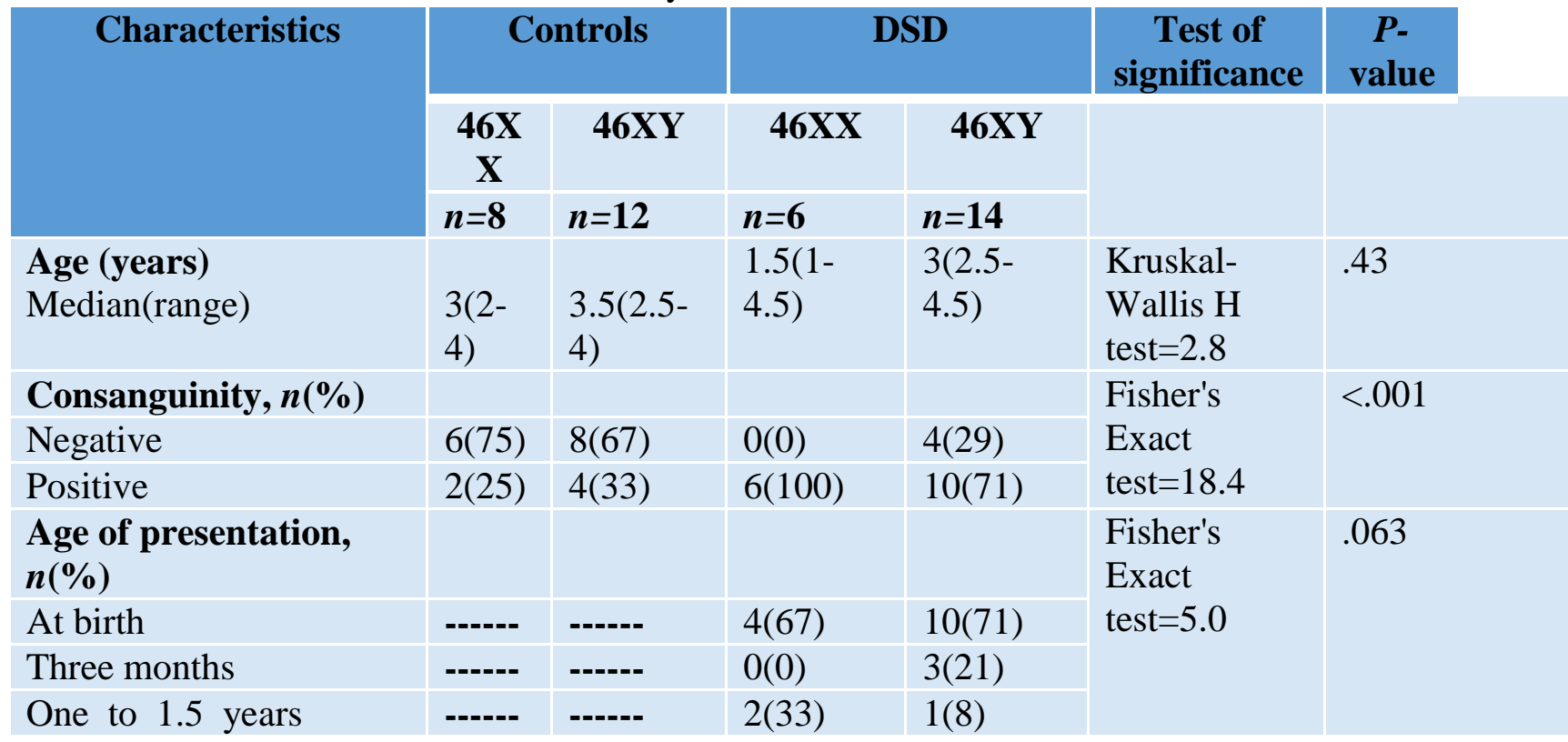

DSD, disorders of sex development,

Table 2. Clinical findings of DSD children

\begin{tabular}{|c|c|c|}
\hline \multirow[t]{3}{*}{ Clinical findings } & \multicolumn{2}{|l|}{ DSD } \\
\hline & $46 X X$ & 46XY \\
\hline & $n=6$ & $n=14$ \\
\hline \multicolumn{3}{|l|}{ Main presentation, $n(\%)$} \\
\hline Absent both testes & $0(0)$ & $8(57)$ \\
\hline Absent one testis & $0(0)$ & $4(29)$ \\
\hline $\begin{array}{l}\text { Dehydration and electrolytes } \\
\text { disturbance }\end{array}$ & $2(33)$ & $0(0)$ \\
\hline Genital ambiguity & $4(67)$ & $0(0)$ \\
\hline $\begin{array}{l}\text { Perineal hypospadias and unilateral } \\
\text { absent testis }\end{array}$ & $0(0)$ & $2(14)$ \\
\hline \multicolumn{3}{|l|}{ Diagnosis, $n(\%)$} \\
\hline $\begin{array}{l}\text { Congenital adrenal hyperplasia } \\
(\mathrm{CAH})\end{array}$ & $6(100)$ & $0(0)$ \\
\hline Isolated bilateral cryptorchidism & $0(0)$ & $4(29)$ \\
\hline Partial gonadal dysgenesis & $0(0)$ & $2(14)$ \\
\hline Perineal hypospadias & $0(0)$ & $4(29)$ \\
\hline Persistent Müllerian duct syndrome & $0(0)$ & $4(29)$ \\
\hline
\end{tabular}

DSD, disorders of sex development, CAH, Congenital adrenal hyperplasia 
Table 3. Investigations (ultrasonography and biopsy) in DSD children

\begin{tabular}{|l|l|l|}
\hline US findings & DSD & $\mathbf{4 6 X Y}$ \\
\hline & $\mathbf{4 6 X X}$ & $\boldsymbol{n}=\mathbf{1 4}$ \\
\hline $\begin{array}{l}\mathbf{n = 6} \\
\text { Ultrasonography, } \boldsymbol{n}(\boldsymbol{\%})\end{array}$ & $0(0)$ & $2(14)$ \\
\hline $\begin{array}{l}\text { Unilateral undescended testis } \\
\text { Unilateral undescended testis with } \\
\text { female genital organ(s) }\end{array}$ & $0(0)$ & $4(29)$ \\
\hline $\begin{array}{l}\text { Bilateral undescended testis } \\
\text { Bilateral undescended testis with } \\
\text { female genital organ(s) }\end{array}$ & $0(0)$ & $6(43)$ \\
\hline $\begin{array}{l}\text { Enlarged adrenal glands } \\
\text { *Gonadal biopsy, } \boldsymbol{n}(\boldsymbol{\%})\end{array}$ & $0(0)$ & $2(14)$ \\
\hline $\begin{array}{l}\text { Bilateral Primitive testes } \\
\text { Unilateral primitive testis with absent } \\
\text { testicular tissue on the other testis. }\end{array}$ & ----- & $0(0)$ \\
\hline & & 2 \\
\hline & & 2 \\
\hline
\end{tabular}

Table 4. Hormonal profile of healthy and DSD children

\begin{tabular}{|c|c|c|c|c|c|c|}
\hline \multirow{3}{*}{$\begin{array}{l}\text { Laborator } \\
\text { y findings }\end{array}$} & Cases & Controls & \multirow{3}{*}{$\begin{array}{l}P \text { - } \\
\text { value }\end{array}$} & Cases & Controls & \multirow[t]{3}{*}{$P$-value } \\
\hline & 46XY & $46 X Y$ & & $46 X X$ & $46 X X$ & \\
\hline & $n=14$ & $n=12$ & & $n=6$ & $n=8$ & \\
\hline $\begin{array}{l}\text { Anti- } \\
\text { Müllerian } \\
\text { hormone } \\
\text { (pmol/L) }\end{array}$ & $315(25-377)$ & $900(300-1020)$ & $<.001 \dagger$ & $19.3 \pm 5.9$ & $20 \pm 4.4$ & $.81 \dagger$ \\
\hline $\begin{array}{l}\text { Testostero } \\
\text { ne } \\
(\mathrm{ng} / \mathrm{mL})\end{array}$ & $\begin{array}{l}0.12(0.07- \\
0.15)\end{array}$ & $\begin{array}{l}0.18(0.16- \\
0.82)\end{array}$ & $<.001 \dagger$ & $0.14 \pm 0.07$ & $0.11 \pm 0.03$ & $.28 \ddagger$ \\
\hline $\begin{array}{l}\operatorname{DHT}(\mathrm{Pg} / \\
\mathrm{mL})\end{array}$ & $14.8 \pm 1.8$ & $27.3 \pm 4.3$ & $<.001 \ddagger$ & $20.5 \pm 5.6$ & $17.8 \pm 1.7$ & $.30 \ddagger$ \\
\hline
\end{tabular}


Table 5. Association between hormonal levels and US findings of male DSD children

\begin{tabular}{|c|c|c|c|c|}
\hline \multirow[t]{3}{*}{ Hormones } & \multicolumn{2}{|l|}{ US findings } & \multirow{3}{*}{$\begin{array}{l}\text { Mann } \\
\text { Whitney } \\
U \text { test }\end{array}$} & \multirow[t]{3}{*}{$P$-value } \\
\hline & $\begin{array}{l}\text { Undescended testis } \\
\text { and female genital } \\
\text { organ }\end{array}$ & $\begin{array}{l}\text { Undescended } \\
\text { testis }\end{array}$ & & \\
\hline & $n=6$ & $n=8$ & & \\
\hline $\begin{array}{l}\text { Anti-Müllerian } \\
\text { hormone } \\
\text { (pmol/L) } \\
\text { median(range) }\end{array}$ & $277.5(25-330)$ & $315(248-365)$ & 13.5 & .19 \\
\hline $\begin{array}{l}\text { Testosterone } \\
\text { (ng/mL) } \\
\text { median(range) }\end{array}$ & $0.11(0.07-0.13)$ & $0.15(0.1-0.15)$ & 14 & .22 \\
\hline $\begin{array}{l}\text { DHT(Pg/mL) } \\
\text { median(range) }\end{array}$ & $13.2(12.7-16.5)$ & $15.4(12.7-17.6)$ & 13 & .18 \\
\hline
\end{tabular}

DHT, dihydro-testosterone,

Table 6. Correlation between anti-Müllerian hormone and testosterone of male DSD children

\begin{tabular}{|l|l|}
\hline Testosterone $(\mathrm{ng} / \mathrm{mL})$ & $\begin{array}{l}\text { Anti-Müllerian hormone } \\
(\mathbf{p m o l} / \mathrm{L})\end{array}$ \\
\hline $\boldsymbol{r}$ & .842 \\
\hline $\boldsymbol{P}$-value & $<.001$ \\
\hline
\end{tabular}

r: Pearson correlation, DSD, disorders of sex development. Total number=14

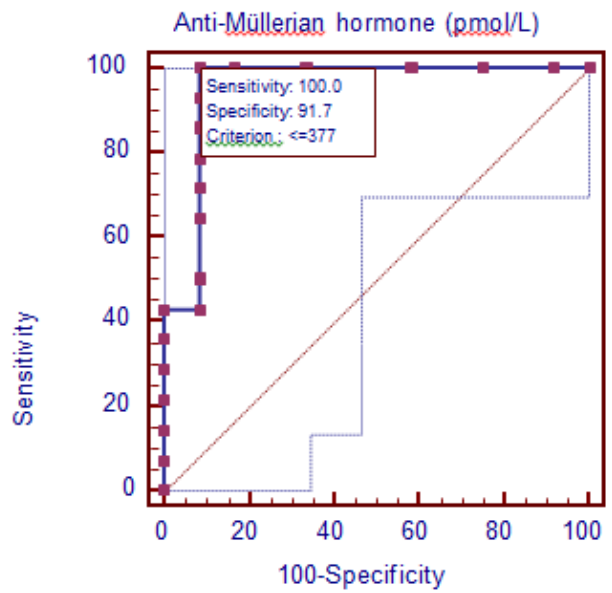

Figure 1. ROC (receiver operating characteristic) curve analysis revealed that area under the curve (AUC) of 0.95 for serum anti-Müllerian hormone (95\% CI: 0.858 to $1.047, \mathrm{P}<.001)$. The optimal sensitivity and specificity were $(100 \%$ and $91.7 \%$ respectively at a cutoff expression value $\leq 377)$. 


\section{DISCUSSION}

Disorders of sex development can be considered as the most confusing anomalies that may face clinicians. Definite diagnosis of these disorders is necessary for proper gender assignment of patients that may help in proper hormonal or surgical treatment needed for proper sexual development. In addition, proper gender assignment prevents social and psychiatric problems that may face the patients throughout their lives as well as their parents [7].

Anti-Müllerian hormone, (AMH) is produced by Sertoli cells in the seventh gestational week to prevent the development of Müllerian ducts during testicular differentiation. It is also secreted in a tiny amount by the granulosa cells in females to initiate and regulate the recruitment of ovarian follicles. Serum levels of $\mathrm{AMH}$ in both sexes vary by age and sex [5].

The present study highlighted the highly significant positive parenteral consanguinity among DSD children in comparison to the healthy children as the positive consanguinity reached $100 \%(6 / 6)$ in DSD females and $71 \%(10 / 14)$ of DSD males in comparison to $25 \%(2 / 8)$ in healthy females and $33 \%(4 / 12)$ in healthy males. The current results were in agreement with that of Mazen et al. [8]. who reported that about $70 \%(145 / 208)$ of cases had a positive consanguinity. Also, Warne and Raza [9]. stated that almost all DSD cases in India have a positive consanguinity and justified that as most of these disorders are results of autosomal recessive inheritance which requires consanguinity to increase its ability to produce DSD.

In the present study, a major handicap to the study is that the only 46,XX DSD, the study was able to reach, was CAH (6/6) and this prevented us from investigating the serum levels of $\mathrm{AMH}$ in the remaining spectrum of other 46,XX DSD. 67\% (4/6) of these $\mathrm{CAH}$ females were presented at birth with ambiguous genitalia while the remaining $33 \%(2 / 6)$ were presented latter with dehydration and electrolyte disturbance. The same results were obtained by Mazen et al. [8]. as almost all cases of 46,XX DSD in their study in Egypt were diagnosed with $\mathrm{CAH}$. Moreover, 46, XX testicular DSD is a very rare condition and about $90 \%$ of cases are diagnosed at puberty or even after marriage [10]. and this is another limitation to the present study as the age scope of the current study included children only between the first day of life and the age of 10 years.

On the other side, the current study revealed that the most frequent main presentation in DSD males is the absence of both testes which represented $57 \%$ $(8 / 14)$ of the entire sample. The current study results revealed also that the most frequent types of 46,XY DSD were isolated bilateral cryptorchidism (29\%; 4/14), perineal hypospadias (29\%; 4/14) and persistent Müllerian duct syndrome (29\%; 4/14). The current results disagree with Mota et al. [11]. who performed a retrospective study on 93 patients -known to be $46, X Y$ DSD with ages varying from 4 days up to 28 years old- and stated that the most frequent type of 46,XY DSD was androgen insensitivity syndrome. However, this disagreement may be explained by the different age scopes of the two studies as androgen insensitivity syndrome is mostly presented at puberty when patients- who own external female genitalia and were reared as femalesdevelop primary amenorrhoea according to Hughes et al. [12]. 
In the present study, there was no significant difference between AMH serum levels in both healthy and DSD females $(\mathrm{P}=.81)$. Such finding was not surprising as all 46,XX DSD females included in the study were diagnosed with $\mathrm{CAH}$ and those patients don't own any testicular tissue as their high titres of androgenic hormones are not products of testicular tissues activity, but accumulation of androgens precursors due inadequate synthesis of adrenal hormones [13]. In addition, 46,XX testicular DSD patientswho are expected to have higher serum titres of AMH- are very rare and rarely diagnosed within the age scope of the current study according to An1k et al. [10].

On the contrary, AMH serum levels showed a very high significant decrease in 46,XY DSD compared with the healthy boys $(\mathrm{P}<.001)$. The same results were declared by Grinspon and Rey [14]. who stated that the serum levels of AMH in boys with anorchia or bilateral undescended testes were unremarkable. In addition, Ahmed et al. [15]. performed a cross section study on 284 children in the United Kingdom and found that boys with dysgenetic testes, bilateral undescended testes and anorchia had a much lower serum levels of AMH compared with their healthy fellows. Furthermore, Matuszczak et al. [16]. performed a case control study on 50 boys -half of them were cryptorchidic boys and the others were normal- then stated that boys with cryptorchidism (unilateral or bilateral) were found to have a significantly decreased AMH levels compared with the healthy control boys. Also, Hafez et al. [17]. reported a significant decrease in serum levels of AMH in boys born with cryptorchidism or anorchia compared with normal healthy males of the same age. However, the previous authors disagreed with the current study results concerning AMH levels in persistent Müllerian duct syndrome as they reported a nearly normal AMH levels in these patients and explained that as the defect in patients with persistent Müllerian duct syndrome is in AMH-receptors not AMH production. However, persistent Müllerian duct syndrome results not only from a defect in AMH receptors but also its production according to Altincik et al. [18]. who stated that persistent Müllerian duct syndrome is caused by a mutation affecting $\mathrm{AMH}$ gene or $\mathrm{AMH}$ receptor gene type II. In addition, Rane et al. [19]. reported that patients with persistent Müllerian duct syndrome have a defect either in production of AMH or its receptors. Furthermore, Kim and Kim [1]. mentioned that DSD patient may have more than one disorder at the same time and this might affect the results as all persistent Müllerian duct syndrome patients included in the current study had a unilateral or bilateral undescended testes which certainly can affect AMH production.

Although $\mathrm{CAH}$ is characterized by elevated levels of adrenal androgens [20]. serum levels of testosterone and DHT in most females diagnosed $\mathrm{CAH}$ in the present study showed no significance difference from healthy control fellows $(\mathrm{P}=.28$, .30 respectively). Only one femalewho was presented for the first time- was found to have higher testosterone and DHT levels. These results were not also surprising as proper hormonal therapy seemed quite successful in reduction the androgenic hormone levels in DSD females utilizing hormonal therapy.

On the other side, serum levels of testosterone and DHT in 46,XY DSD showed a significant drop when compared with healthy boys $(\mathrm{P}<.001)$. Hafez et al. 
[17]. reported that serum levels of testosterone in 46,XY DSD were found to be significantly lower than normal.

In the present study, there was a significantly positive strong correlation between $\mathrm{AMH}$ and testosterone levels $(\mathrm{P}=.004)$.

In the present work, $\mathrm{AMH}$ was found to be a good tool in denying existence of functioning testicular tissues in 46,XX DSD patients as its level wasn't affected compared with control girls- in cases of CAH where testosterone and DHT levels fluctuating by the act of following or not following a regular hormonal therapy. These findings may give a superiority of AMH over androgenic hormones in evaluating the function of testicular tissues in $46, X X$ DSD patients.

In the present study, the best cut-off value for $\mathrm{AMH}$ in discriminating between the existence and absence of functioning testicular tissues was $377 \mathrm{pmol} / \mathrm{L}$. The sensitivity and specificity were $100 \%$ and $91.7 \%$ respectively. The area under the curve (AUC) reached $0.95 \quad(\mathrm{P}<.001)$. Similar results were obtained by $\mathrm{Hafez}$ et al. [17]. as they reported that the cut-off value for $\mathrm{AMH}$ discriminating between the existence and absence of functioning testicular tissues was $200 \mathrm{pmol} / \mathrm{L}$ with a sensitivity of $97 \%$ and a specificity of $70 \%$, while the AUC reached 0.90 .

Although these findings indicated that serum AMH can be considered as a potential diagnostic biomarker in 46,XY DSD patients below ten years, both testosterone and DHT for the same patients had a much better role as the optimal sensitivity and specificity of them were $100 \%$ for both. This finding indicated that AMH has a better diagnostic role in 46,XX DSD than 46,XY DSD patients while on the other side the opposite is present with testosterone and DHT.
The current study revealed that $\mathrm{AMH}$ can give rapid reliable data about the testicular existence and function and it can be used as potential diagnostic biomarker in childhood 46,XX DSD below ten years. However, the study revealed also that the cheaper serum testosterone and DHT investigations had a better diagnostic role in 46.XY DSD than AMH.

\section{Declaration of interest}

The authors report no conflicts of interest. The authors alone are responsible for the content and writing of the paper.

Funding information: None declared

\section{REFERENCES}

1. Kim KS and Kim: Disorders of Sex Development. Korean Journal of Urology 2012; 53(1):1-8.

2. Kling JM, Rose SH, Kransdorf LN, Viggiano TR, Virginia $M$ and Miller VM: Evaluation of sex- and gender-based medicine training in post-graduate medical education: a crosssectional survey study. Biology of Sex Differences 2016; 7: 1-3.

3. Turcu AF and Auchus RJ: Adrenal Steroidogenesis and Congenital Adrenal Hyperplasia. Endocrinology and Metabolism Clinics of North America 2016; 44(2): 275296.

4. Albalushi H, Sahlin L, Åkesson E, Kurek, M, Kjartansdóttir KR, Lindh R, et al.: Hormone production by human first-trimester gonads in a functional in vitro system. Journal of Endocrinology 2018, 159(11): 1-6.

5. Grinspon RP and Rey R: Anti-Mullerian“ hormone and Sertoli cell function in pediatric male hypogonadism. Hormone Research in Pediatrics 2010, 73(2): 81-92.

6. Kirkwood BK; and Sterne JAC: Essential medical statistics. 2nd edition, Blackwell Science, Inc 2003. Pp: 33-43

7. Khorashad BS, Khazai BR, Ghasem MH, Mehran A, Mozhgan V and Tim C: Prenatal Testosterone and Theory of Mind Development: Findings from Disorders of Sex Development. Psychoneuroendocrinology 2018; 89:250-255

8. Mazen I, Hiort O and Bassiouny R: Differential 
diagnosis of disorders of sex development in Egypt. Hormone Research in Pediatrics 2008, 70(2): 118-123.

9. Warne GL and Raza J: Disorders of sex development (DSDs), their presentation and management in different cultures. Reviews in Endocrine and Metabolic Disorders 2008, 9(3):227-36.

10. Anık A, Çatlı G, Abacı A and Böber E: $46, X X$ male disorder of sexual development: a case report. Journal of Clinical Research İn Pediatric Endocrinology 2013; 5(4):258-60.

11. Mota BC, Oliveira LM, Lago $R$, Brito $P$, Canguçú-Campinho AK, Barroso U, et al.: Clinical profile of 93 cases of 46, XY disorders of sexual development in a referral center. International Brazilian Journal of Urology 2015; 41(5): 975-981.

12. Hughes LA, Davies JD, Bunch TI, Pasterski V, Mastroyannopoulou $\mathrm{K}$ and MacDougall J: Androgen insensitivity syndrome. Lancet Journal 2012; 380(9851): 1419-1428.

13. Holcomb GW, Murphy JP and Ostlie DJ: Chapter 63 Disorders of sexual differentiation. 5th edition, Saunders, 2010. Pp: 805-816.

14. Grinspon RP and Rey R: New perspectives in the diagnosis of pediatric male hypogonadism: the importance of $\mathrm{AMH}$ as a Sertoli cell marker. Arquivos Brasileiros de Endocrinologia \& Metabologia 2011; 55: 512 519.

15. Ahmed SF, Achermann JC, Arlt W, Balen AH, Conway G, Edwards ZL, et al.: UK guidance on the initial evaluation of an infant or an adolescent with a suspected disorder of sex development. Clinical Endocrinology 2011; 75(1): 12-26.

16. Matuszczak E, Hermanowicz A, and Debek W: Serum AMH concentration as a marker evaluating gonadal function in boys operated on for unilateral cryptorchidism between 1st and 4th year of life-why patients with inguinal hernia served as controls. Endocrine Journal 2012, 41(3): 544-5.

17. Hafez M, El-Dayem SM, El-Mougy F, Atef A, Kandil M, Galal, A, et al.: The role of antiMullerian and inhibin B hormones in the evaluation of 46,XY disorders of sex development. Journal of Pediatric Endocrinology and Metabolism 2014; 27(9):891-899.

18. Altincik A, Karaca $\mathrm{F}$ and Onay $\mathrm{H}$ : Persistent Müllerian duct syndrome: A novel mutation in the Anti-Müllerian Hormone gene. Hormones 2017; 16(2): 205-208.

19. Rane SR, Dangmali DP, Vishwasrao SD and Puranik SC: Persistent Mullerian Duct Syndrome with Testicular Seminoma in Transverse Testicular Ectopia. Journal of human reproductive sciences 2018, 11(3): 300302.

20. Witchel SF: Genetics and Pathophysiology of Congenital Adrenal Hyperplasia. In: Levine A. (eds) Adrenal Disorders. 1st edition, Cham, 2018. Pp: 109-127.

To Cite This Article: Hossam MK, Ashgan AA, Ebtehag HH, Ibrahim SI.Value of Anti-Müllerian Hormone in Diagnosis and Management of Children with Disorders of Sex Development.ZUMJ 2020;26(1);114-122.DOi: 10.21608/zumj.2019.11117.1163 